\title{
Malignant glaucoma
}

\section{Glaucoma maligno}

Sebastião Cronemberger, ${ }^{1}$ Nassim Calixto, ${ }^{1}$ Alberto Diniz Filho ${ }^{2}$

\begin{abstract}
The aim of this review is to discuss current knowledge about pathophysiology and clinical, therapeutic and prophylactic approaches for malignant glaucoma. This type of glaucoma can occur after different surgical procedures. It can also occur in aphakic, phakic and pseudophakic eyes and develop spontaneously in individuals with no ocular surgical history, or associated with topical miotics. Currently, the ultrasound biomicroscopy has provided many interesting and useful findings for diagnosis and monitoring the treatment of malignant glaucoma. It occurs more often in short eyes in which pre operative measurements of the anterior chamber depth and axial length are extremely important for its prophylaxis and diagnosis.

Keywords: Glaucoma; Glaucoma, angle-closure/diagnosis; Glaucoma, angle-closure/classification; Glaucoma, angle-closurel physiopathology; Glaucoma, angle-closure/therapy; Glaucoma, angle-closure/surgery; Glaucoma, angle-closure/uUltrasonography; Prophylaxis
\end{abstract}

\section{Resumo}

O objetivo deste artigo de revisão é discutir o conhecimento atual sobre a fisiopatologia e as abordagens diagnóstica, terapêutica e profilática do glaucoma maligno. Este tipo de glaucoma pode ocorrer após diferentes procedimentos cirúrgicos. Pode ocorrer em olhos áfacos, fácicos e pseudofácicos e se desenvolver espontaneamente em olhos não-operados, ou associado ao uso de mióticos. Atualmente, a biomicroscopia ultrassônica tem revelado muitos achados úteis e importantes para o diagnóstico e o tratamento do glaucoma maligno. Ele ocorre com maior frequência em olhos pequenos nos quais as medidas pré-operatórias da profundidade da câmara anterior e do comprimento axial são extremamente importantes para a sua profilaxia e diagnóstico.

Descritores: Glaucoma; Glaucoma de ângulo fechado /diagnóstico; Glaucoma de ângulo fechado /classificação; Glaucoma de ângulo fechado /fisiopatologia; Glaucoma de ângulo fechado/terapia; Glaucoma de ângulo fechado/cirurgia; Glaucoma de ângulo fechado/ultrasonografia; Profilaxia

${ }^{1}$ Universidade Federal de Minas Gerais (UFMG) - Belo Horizonte (MG), Brasil;

${ }^{2}$ Universidade Federal de Minas Gerais (UFMG) - Belo Horizonte (MG), Brasil.

Interest conflict - None

Recebido para publicação em 7/4/2011 - Aceito para publicação em 16/2/2012 


\section{INTRODUCTION}

$\mathbf{M}$ alignant glaucoma is, among all types of glaucoma, one of the most feared by ophthalmologists because of its resistance to clinical or surgical treatment and, consequently, its enormous potential to cause loss of vision. In 1869, Von Graefe $^{(1)}$ was the first to coin the term "Glaucoma malignum" to describe an unpredictable complication which had occurred in $2 \%$ of his patients. They had simple glaucoma and had undergone peripheral iridectomy. $\mathrm{He}$ outlined the following characteristics in this type of glaucoma: 1) a very elevated pre operative intraocular pressure (IOP) that remained high after surgery or even increased; 2) a flat anterior chamber; 3) marked corneal edema visible with the naked eye; 4) rapid vision loss. Heuser $^{(2)}$ was the first to use $10 \%$ atropine eye drops in one eye that developed acute post operative hypertension following an iridectomy. On the following day, the anterior chamber was reformed and the IOP was controlled. At the three-month follow-up, the eye did not present any problem.

In general, malignant glaucoma occurs more frequently $(2-4 \%)$ in eyes with angle-closure glaucoma and is extremely resistant to medical or surgical treatment ${ }^{(3)}$. It is precisely this great resistance to treatment that led Von Graefe $e^{(1)}$ to use the term "Glaucoma malignum", also known as ciliary block glaucoma ${ }^{(3)}$. The term ciliary block glaucoma is used in order to alert the physician to the anatomical structure responsible for its pathogenesis. $^{(3)}$ It makes the disease less alarming to the patient, eliminating the idea of a malignant neoplastic disease. Since the 1960s the incidence of malignant glaucoma has notably decreased. Currently, the low incidence of malignant glaucoma is due to advances in knowledge, improvement in management provided by new antiglaucomatous medications, argon and Nd:YAG lasers, phacoemulsification and ultrasound biomicroscopy (UBM).

In this review we will specifically address the different causes of malignant glaucoma as well as the techniques used for diagnosis, treatment and prophylaxis.

\section{General considerations}

The synonymy of malignant glaucoma includes: glaucoma caused by misdirection of aqueous humor into the posterior segment ${ }^{(4)}$, ciliary block glaucoma ${ }^{(3)}$, ciliolenticular block glaucoma ${ }^{(5)}$ and glaucoma due to vitreous ciliary block ${ }^{(6)}$. More recently, the terms vitreous expansion glaucoma or vitreous displacement glaucoma have been suggested ${ }^{(7)}$.

Traditionally, malignant glaucoma occurs with higher incidence in patients who were operated for acute primary glaucoma. However, Hutchinson and Smith ${ }^{(8)}$ and one of us $\left(\right.$ Calixto $\left.^{(9,10)}\right)$ independently published the first observations of malignant glaucoma after cataract surgery in eyes not previously glaucomatous. The clinical picture and treatment of the crises were the same. There are reports of malignant glaucoma which occurred after iridectomy ${ }^{(1,7)}$ trabeculectomy, ${ }^{(9)}$ cataract surgery with or without intraocular lens implantation, ${ }^{(8-11)}$ needling of trabeculec-tomy, ${ }^{(12)}$ drain valves ${ }^{(13)} \mathrm{Nd}$ :YAG laser posterior capsulotomy, ${ }^{(14)}$ intravitreal triamcinolone acetonide, ${ }^{(15)}$ intracameral perfluoropropane tamponade. ${ }^{(16)}$ Also, there are reports of malignant glaucoma developing spontaneously (17) in individuals with no surgical history, or associated with topical miotics. ${ }^{(18)}$ Malignant glaucoma can occur in aphakic, phakic and pseudophakic eyes and may develop during surgery, weeks or even years afterwards. (1,2,8-20) $^{(1)}$

\section{Classification}

In 1972, one author ${ }^{(19)}$ proposed a classification of malignant glaucoma into two groups: 1 . Classic malignant glaucoma in which the clinical manifestations are similar to those originally described. 2. Modern malignant glaucoma which is subdivided into primary and secondary according to known precipitating factors such as injury, miotic eye drops, inflammation and reading. ${ }^{(19-22)}$ The original definition described a clinical condition characterized by a blockage of the normal flow of aqueous humor which results in its accumulation within the vitreous. It is etiologically related to abnormalities of the ciliary body, choroid, lens, vitreous and zonule. In general, after glaucoma surgery, the onset of malignant glaucoma coincides with the discontinuation of cycloplegic eye drops or at the start of the use of topical miotics. ${ }^{(10,18-22)} \mathrm{A}$ flat or shallow anterior chamber along with the anteriorization of the iridolenticular diaphragm with subsequent occlusion of the angle is associated with a sudden rise in IOP. The IOP levels are generally high, ranging between 40 and 60 $\mathrm{mmHg}$. Iris bombeé due to pupillary seclusion is not present. Hyperemia and edema of the conjunctiva and bullous keratopathy are also common manifestations associated with severe ocular hypertension. Parallelly, the patient presents decreased vision, vision of haloes, photophobia, and lacrimation. The other eye has a tendency to develop in the same manner as that of the initially affected eye. ${ }^{(19)}$ Malignant glaucoma may persist in the eye that had the lens extracted in order to treat the crisis. In aphakic eyes, characteristics and behavior are similar to those of phakic eyes. One author ${ }^{(19)}$ believes that a high IOP prior to surgery is a real indicator of a possible occurrence of malignant glaucoma. He also reported that the incidence of malignant glaucoma is higher in individuals who, despite adequate control of their IOP after an acute crisis, continue having a partially or fully closed angle ${ }^{(19)}$.

\section{Pathophysiology}

\section{Vitreous, ciliary body and ciliary processes}

It was suggested that in eyes with malignant glaucoma, aqueous humor is misdirected to the vitreous body, forming aqueous pocket ${ }^{(20)}$. Consequently, there increased pressure in the vitreous cavity, which leads to an anterior displacement of the iridolenticular diaphragm. 
This is accompanied by a flat or shallow anterior chamber, angle closure and the development of clinical characteristics of malignant glaucoma. Some authors ${ }^{(3,4,22)}$ observed that eyes with malignant glaucoma have interesting features in relation to the anterior vitreous, ciliary processes and lens periphery. The ciliary processes are often rotated anteriorly, coming in close contact with the lens equator. In spite of an abnormal relationship between the ciliary processes and the lens, this fact is not, in itself, enough to block the flow of aqueous humor into the anterior chamber ${ }^{(20)}$. The vitreous' dislocation appears to be vital in this process due to its anomalous relationship with the lens periphery and ciliary processes. It causes a diversion of the aqueous humor flow from an anterior to a posterior route(20). One experimental study ${ }^{(23)}$ with vitreous infusion in enucleated human eyes and in calf eyes showed a decrease in vitreous permeability with increasing perfusion pressure. The presence of an elevated pressure is due to the increased volume of the vitreous caused by the aqueous humor pockets. These can press the anterior hyaloid membrane against the ciliary body, thereby reducing the area through which the aqueous humor can flow anteriorly. Therefore, an abnormal retention of aqueous humor in the vitreous cavity can occur due to an impermeable anterior hyaloid membrane that causes an expansion and forward displacement of the vitreous body. Based on these data, some authors ${ }^{(24)}$ propose a sequence of events responsible for malignant glaucoma which starts with the formation of aqueous humor pockets in the vitreous space. Consequently, there is compression and reduction of the vitreous permeability which increases the amount of aqueous humor. This fact causes a compression of the anterior vitreous gel leading to an anterior displacement of the iridolenticular diaphragm. Furthermore, there is a paper ${ }^{(6)}$ reporting a relative laxity of the zonule, spontaneous or induced by miotics. This is sometimes associated with zonular disruptions, favoring the shift of the iridolenticular diaphragm. In summary, the details of the pathophysiology that lead to pockets of aqueous humor in the vitreous spaces remain unclear.

\section{Ultrasound biomicroscopy (UBM) findings}

With the advent of UBM it was possible, in malignant glaucoma, to confirm the anterior rotation of the ciliary processes in close contact with the lens equator ${ }^{(25-27)}$. Some authors $^{(25)}$ used UBM to study the events that occurred at the onset of malignant glaucoma. UBM images revealed that the mechanism of malignant glaucoma is associated with an abnormal relationship among the anterior vitreous, ciliary processes and the lens periphery. Also, the presence of aqueous humor shown by UBM in the supraciliary space (supraciliary effusion) is responsible for the approximation of the ciliary processes to the lens periphery. It is one of the factors which cause ciliolenticular block glaucoma. ${ }^{(24)}$ Other authors ${ }^{(26,27)}$ demonstrated through UBM an annular uveal (choroidal) detachment and discrete supraciliary effusion favoring the anterior dislocation of the iridolenticular diaphragm in approximately half of the eyes with malignant glaucoma. Their findings were consistent with at least two distinct mechanisms that may be responsible for malignant glaucoma. In the first, ciliary detachment is absent or, if present, is not sufficient by itself to cause anterior rotation of the ciliary body and secondary angle closure. Aqueous misdirection plays a major role in the forward displacement of the ciliary body in these eyes. In the second, clinically indistinguishable from the first by slitlamp biomicroscopy, ophthalmoscopy, or contact B-scan ultrasonography, the main factor in the anterior rotation of the ciliary body is a detachment of the ciliary body by supraciliary fluid ${ }^{(27)}$. Hypothetically, cases of malignant glaucoma that respond to medical therapy are more likely to have had ciliary body detachment rather than vitreociliary block as the primary cause ${ }^{(27)}$.

\section{Anatomical features}

Eyes with malignant glaucoma have shown wellknown anatomical features ${ }^{(28-31)}$. From the standpoint of biometrics, eyes with malignant glaucoma present a shorter axial length than found in eyes with open-angle glaucoma and normal eyes, along with a smaller radius of the cornea's curvature, a flat or shallow anterior chamber. In one paper, ${ }^{(28)}$ the authors discovered that the axial length of eyes with malignant glaucoma dropped from $21.60 \mathrm{~mm}$ to $20.42 \mathrm{~mm}$. when they considered three cases of microphthalmos in the statistical analysis. They concluded that eyes with malignant glaucoma are shorter than those eyes with angle-closure glaucoma. ${ }^{(28,29)}$ The biometry of 37 eyes with malignant glaucoma performed by another author ${ }^{(30)}$ showed a mean axial length of $21.7 \mathrm{~mm}$. Therefore, one can predict the risk of malignant glaucoma before surgery in short eyes. In another paper ${ }^{(31)}$, the authors, studying biometric data in eight eyes with malignant glaucoma, found a range in the axial length from 20.7 to $23.1 \mathrm{~mm}$ (mean of $22.1 \mathrm{~mm}$ ), confirming that in practical terms, biometry is an important tool in clinical and surgical management of eyes with these characteristics. However, despite the fact of the prevalence of malignant glaucoma, most often in eyes with a reduced axial length, it has also occurred in eyes with an axial length of $23.1 \mathrm{~mm}$, considered within the normal range. ${ }^{(31)}$ This aspect shows that biometry, despite revealing valuable semiologic data in those eyes, does not precisely define which eye may or may not develop malignant glaucoma. ${ }^{(31)}$ However, eyes with an axial length of $19 \mathrm{~mm}$ or less are at high risk of developing malignant glaucoma when submitted to any type of intraocular surgery.

\section{Work-up}

Beyond the routine eye examination a patient suspected of malignant glaucoma needs to be submitted to the following work-up:

\section{Biomicroscopy with a 3-mirror Goldmann lens}

This exam can reveal areas of the vitreous, optically 


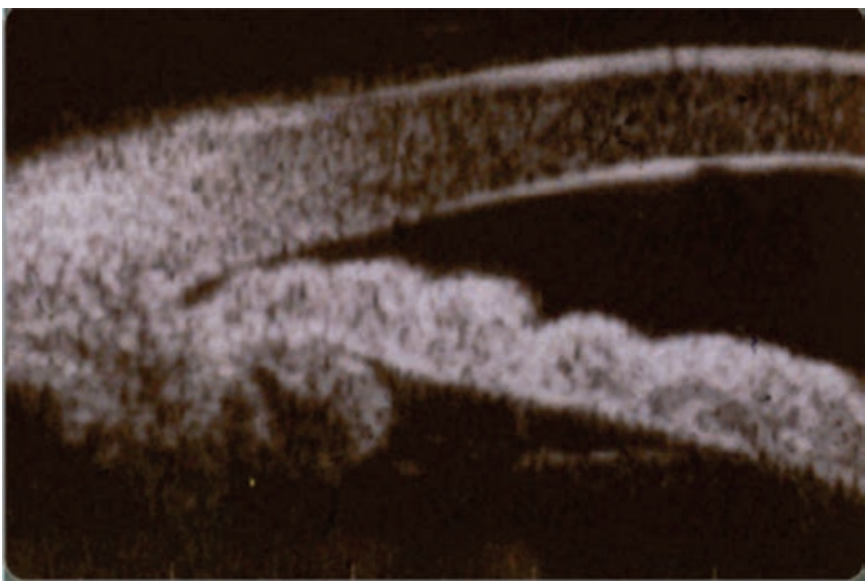

Figure 1: UBM image of plateau iris configuration showing an anterior rotation of the ciliary body along with the disappearance of the ciliary sulcus

empty, which are interpreted as intravitreal pockets of aqueous humor ${ }^{(7,9,10)}$. The posterior vitreous is often detached out of the collections of aqueous humor and behind the posterior hyaloid. Therefore, a biomicroscopic study of the vitreous cavity using the 3-mirror Goldmann lens can possibly show intravitreous or subhyaloid collections of aqueous humor ${ }^{(9,10)}$.

\section{Ultrasonic biometry}

It is a very important and essential exam taking into consi-deration that, in general, eyes with malignant glaucoma are shorter than those with other types of glaucoma and normal eyes. In one study of 37 eyes with malignant glaucoma, the mean axial length was $21.7 \mathrm{~mm} .^{(30)}$ This value is equal or closer to those found in two studies of eyes with acute primary angle-closure $(21.7 \mathrm{~mm}$ and 21.5 $\mathrm{mm}$ ) and lower than that found in eyes with open-angle glaucoma $(23.1 \mathrm{~mm})^{(32,33)}$. The axial length of $21.7 \mathrm{~mm}^{(30)}$ was exactly equal to that found in eyes with plateau iris configuration $^{(34)}$. Some studies based on UBM examinations report that in malignant glaucoma an anterior rotation of the ciliary body occurs along with the disappearance of the ciliary sulcus. ${ }^{(25,26)}$ These findings are similar to what is observed in plateau iris configuration ${ }^{(34)}$ (Figure 1). By the same token, peripheral iridectomy is unsuccessful in eyes with malignant glaucoma as well as in eyes with plateau iris syndrome. This means that it is possible that, in the past, some patients who were diagnosed as having malignant glaucoma could have had, in fact, plateau iris syndrome. Therefore, UBM studies are needed to clarify the role of plateau iris configuration in the pathomecha-nism of malignant glaucoma.

\section{Ultrasound Biomicroscopy (UBM)}

This method of imaging has provided many interesting and useful findings for diagnosis and monitoring the treatment of malignant glaucoma ${ }^{(25-27,35-37)}$. UBM can reveal the following changes: anterior rotation of ciliary body, absence of ciliary sulcus, increased ciliary body thickness, fluid in the supraciliary space (supraciliary effusion), annular ciliary body detachment and obstruction of the trabeculectomy osteum by cilary processes ${ }^{(25,27)}$. Eyes presenting an annular ciliary body detachment along with an IOP that is not markedly elevated should be suspected of malignant glaucoma ${ }^{(27)}$. After hyaloidotomy with $\mathrm{Nd}$ :YAG laser in case of pseudophakic malignant glaucoma, UBM examination ${ }^{(35)}$ shows the return of the ciliary body to its normal position. UBM is also valuable in differentiating pupillary block glaucoma from malignant glaucoma ${ }^{(36,37)}$.

\section{Treatment}

\section{Clinical treatment}

This type of treatment must be rapidly done immediately after the diagnosis of malignant glaucoma. One author ${ }^{(20)}$ considers that the best clinical treatment of malignant glaucoma is the simultaneous use of cycloplegic, midryatics and beta-blockers eye drops, oral carbonic anhydrase inhibitors and hyperosmotic agents. He recommends $1 \%$ atropine eye drops (one drop four times a day), $10 \%$ phenylephrine eye drops (one drop four times a day), $0.5 \%$ timolol eye drops (one drop twice a day); hyperosmotic agents such as mannitol(21) on the maximum tolerable dose (every 12 hours), oral carbonic anhydrase inhibitors in the maximum tolerable dose. Two percent dorzolamide (topical carbonic anhydrase inhibitor) might be an option for patients intolerant to oral acetazolamide. Prostaglandine analogues should not be used because of hyperemia already present. It is recommended that the patient does not ingest food or liquids two hours before and after the use of hyperosmotic agents in order of not altering the osmotic effect of the medication. The combination of these drugs dehydrates the vitreous, reduces aqueous humor production and helps the iridolenticular diaphragm to return to its original position. The exact combination of drugs depends on the patient's clinical response. Treatment should be rigorous until the anterior chamber is reformed as well as adequate control of IOP is achieved. The successful rate of clinical treatment was of $50 \%{ }^{(20)}$. Discontinuation of treatment is initially done with hyperosmotic agents, followed by oral carbonic anhydrase inhibitors, and lastly, followed by beta blockers. The use of a cycloplegic eye drops, particularly $1 \%$ atropine, should be permanent in order to prevent the malignant glaucoma's recurrence.

\section{Laser treatment}

The rupture of the anterior hyaloid membrane (hyaloidectomy) with $\mathrm{Nd}$ :YAG laser is the treatment of choice for malignant glaucoma in aphakic or pseudophakic eyes ${ }^{(38,39)}$. Laser photocoagulation of the ciliary processes can also be performed in an attempt to reverse malignant glaucoma ${ }^{(40)}$. Photocoagulation of the ciliary processes causes a localized disruption of the ciliary block which allows the flow of aqueous humor into the anterior chamber. This leads to the start of the anterior chamber reformation which is completed in three to 
five days after laser treatment. If necessary, Nd:YAG laser is performed after using glycerin eye drops to reduce or eliminate corneal edema ${ }^{(38,39)}$. Transscleral diode laser cyclophotocoagulation can be also used ${ }^{(41)}$.

\section{Surgical treatment}

\section{Pars plana vitrectomy}

It is a successful surgical treatment for malignant glaucoma ${ }^{(42-46)}$. The vitreous punction and aspiration is performed via pars plana four $\mathrm{mm}$ from the limbus with an 18-gauge needle and is associated with the reformation of the anterior chamber with saline or viscoelastic substance. This technique has been used in many eyes with good results. A pars plana vitrectomy has several advantages in relation to other surgical techniques. The removal of the vitreous after opening of the anterior hyaloid membrane minimizes the risk of recurrence of the misdirection of aqueous humor. Vitrectomy can be performed via pars plana or through limbus ${ }^{(42)}$. This surgery allows the aspiration of the vitreous without removing the transparent crystalline lens. ${ }^{(42)}$ For some authors ${ }^{(43)}$, pars plana vitrectomy showed better results in resolving ciliary block glaucoma in pseudophakic eyes than in phakic eyes. In phakic eyes, lensectomy may be considered for marked corneal edema, for dense cataract, or when the anterior chamber do not deepen during vitrectomy ${ }^{(44)}$. More recently, other authors ${ }^{(45)}$ have performed pars plana vitrectomy. They reported positive results in $67 \%$ of pseudophakic eyes but only in $25 \%$ of phakic eyes with malignant glaucoma. Such results are justified because in phakic eyes it is difficult to perform vitrectomy in the region of the anterior hyaloid membrane. This situation increases the chances of accidental injury to the lens. Besides this, the procedure is performed "blindly" and is susceptible to complications such as retinal and/or choroidal detachment and vitreous hemorrhage. In order to avoid these complications, pars plana vitrectomy with lensectomy or phacoemulsification or extracapsular cataract extraction was introduced and has been widely used in the surgical treatment of malignant glaucoma ${ }^{(45,46)}$.

\section{Combined cataract extraction and vitrectomy}

Cataract extraction combined with vitrectomy can be performed in three different ways: pars plana vitrectomy associated with lensectomy, extracapsular cataract extraction with posterior capsulotomy associated with anterior vitrectomy, and phacoemulsification with posterior capsulotomy plus anterior vitrectomy. These surgeries are successful. Some authors ${ }^{(46)}$ concluded that vitrectomy via pars plana associated with lensectomy had a success rate of $100 \%$ compared to the $71 \%$ success rate without lensectomy. The extracapsular cataract extraction combined with vitrectomy and maintenance of the posterior capsule had success rates of $17 \%$ compared to $83 \%$ in which the primary posterior capsulotomy was performed. They conclude that, due to the low rate of successful vitrectomies associated with intact posterior capsule, it is recommendable that vitrectomy be associated with extracapsular cataract extraction or phacoemulsification with primary posterior capsulotomy in order to allow an adequate opening of the anterior hyaloid membrane ${ }^{(46)}$.

\section{New surgeries}

A new surgical treatment for pseudophakic malignant glaucoma called zonulo-hyaloido-vitrectomy has been proposed $^{(47)}$. It consists of zonulectomy, hyaloidectomy and anterior vitrectomy through iridectomy via the anterior chamber. An access route is created between the anterior chamber and vitreous cavity with the use of a vitreousphage $\mathrm{A}^{(4)}$. In combination, a continuous infusion cannula is fitted into the anterior chamber through a paracentesis, in order to deepen and maintain that space during the procedure. The success rate of the procedure performed on five patients with pseudophakic malignant glaucoma was $100 \%{ }^{(47)}$. Another surgery ${ }^{(7)}$ named transcorneal needle disruption consists of opening the peripheral anterior hyaloid membrane through the peripheral iridectomy using a needle. This procedure was successfully performed in two cases of malignant glaucoma ${ }^{(7)}$. In conclusion, whatever the true underlying mechanism, the fact is that malignant glaucoma is reversed when an opening in the anterior hyaloid membrane is done allowing direct communication between the anterior chamber and vitreous cavity.

\section{Prophilaxis}

The major challenges in malignant glaucoma are its resolution and the prevention of its recurrence. In short eyes prone to malignant glaucoma, the systematic use of $1 \%$ atropine eye drops during and after glaucoma or cataract surgery with lens implantation is imperative for its prevention. Cycloplegic eye drops should be used post operatively for some weeks or months or permanently ${ }^{(19)}$. Topical miotics ${ }^{(19)}$ and prostaglandin analogs are contraindicated. If the IOP is very high, it is necessary to take measures in order to reduce it before intraocular surgery ${ }^{(20)}$. One author ${ }^{(48)}$ advocates the decompression of vortex veins during the trabeculectomy in nanophthalmic eyes in order to prevent malignant glaucoma.

\section{The fellow eye}

In general, the contralateral eye is likely to develop malignant glaucoma as well ${ }^{(19)}$. If intraocular surgery is needed in this eye, the same prophylactic measures are indispensible for the prevention of malignant glaucoma. Pars plana vitrectomy combined with cataract extraction has been described for the management of cataract in fellow eyes at high risk of developing malignant glaucoma ${ }^{(49)}$.

\section{ConClusion}

Malignant glaucoma is an emergency. It occurs more often in short eyes in which pre operative measurements of 
the anterior chamber depth and axial length are extremely important for its prophylaxis and diagnosis. In eyes prone to malignant glaucoma the systematic use of $1 \%$ atropine eye drops during and after ocular surgery is imperative for its prevention. When clinical treatment fails, the best surgical approach depends on the cause of malignant glaucoma. The treatment of choice in aphakic or pseudophakic eyes is rupture of the anterior hyaloid membrane with the Nd:YAG laser.

\section{REFERENCES}

1. Von Graefe A. Beiträge zur pathologie und therapie des glaukoms. Graefes Arch Clin Exp Ophthalmol. 1869;15:108-252.

2. Heuser V. Atropin-Gebrauch bein Glaukom. Zentraibl f prakt Ophthalmol VersammÍ. 1877;1:256-7.

3. Weiss DI, Shaffer RN. Ciliary block (malignant) glaucoma. Trans Am Acad Ophthalmol Otolaryngol. 1972;76(2):450-61.

4. Shaffer RN, Hoskins HD Jr. Ciliary block (malignant) glaucoma. Ophthalmology. 1978;85(3):215-21.

5. Wollensak J, Pham DT, Anders N. [Ciliolenticular block as a late complication in pseudophakia]. Ophthalmologe. 1995;92(3):2803. German.

6. Chandler PA. Malignant glaucoma. Trans Am Ophthalmol Soc. 1951:128-43.

7. Francis BA, Wong RM, Minckler DS. Slit-lamp needle revision for aqueous misdirection after trabeculectomy. J Glaucoma. 2002;11(3):183-8.

8. Hutchinson BT, Smith TR. Hyaloid block glaucoma. Proc N Engl Ophthalmol Soc. Boston, Mass., April, I967.

9. Calixto N. Glaucoma maligno. In: VIII Congresso Pan-Americano de Oftalmologia; 1968, marzo, 24 a 30, Mar del Plata, Argentina. Anais. Mar del Plata. 1968. v. II. p. 114-7.

10. Calixto N. Glaucoma maligno. In: Carvalho MH, Giardulli A, organizadores. Jubileu magisterial do Professor Antonio Paulo Filho. Rio de Janeiro: Borsoi; 1976. p. 256-80.

11. Pierre Filho PTP, Rodrigues FKP, Ferreira EL. Glaucoma maligno após extração de catarata com implante de lente intra-ocular. Rev Ciênc Méd (Campinas). 2003;12(3):275-8.

12. Mathur R, Gazzard G, Oen F. Malignant glaucoma following needling of a trabeculectomy bleb. Eye (Lond). 2002;16(5):667-8.

13. Martínez-de-la-Casa JM, García-Feijoó J, Castillo A, Polo V, Larrosa JM, Pablo L, García-Sánchez J. Glaucoma maligno tras cirugía combinada de implante valvular de Ahmed y facoemulsificación en el tratamiento del glaucoma crónico por cierre angular. Arch Soc Esp Oftalmol. 2005;80(11):667-70.

14. Arya SK, Sonika, Kochhar S, Kumar S, Kang M, Sood S. Malignant glaucoma as a complication of Nd:YAG laser posterior capsulotomy. Ophthalmic Surg Lasers Imaging. 2004;35(3):248-50.

15. Heatley CJ, Lim KS, Siriwardena D, Barton K. Malignant glaucoma as a complication of intravitreal triamcinolone acetonide. Acta Ophthalmol Scand. 2006;84(5):712-3.

16. Vanathi M, Mohan S, Dada T, Panda A. Malignant glaucoma after intracameral isoexpansile perfluoropropane tamponade for the management of acute corneal hydrops. Cornea. 2010;29(7):8389; author reply 839-40. Comment on Cornea. 2009;28(3):317-20.

17. Fanous S, Brouillette G. Ciliary block glaucoma: malignant glaucoma in the absence of a history of surgery and of miotic therapy. Can J Ophthalmol. 1983;18(6):302-3.

18. Rieser JC, Schwartz B. Miotic-induced malignant glaucoma. Arch Ophthalmol. 1972;87(6):706-12.

19. Levene R. A new concept of malignant glaucoma. Arch Ophthalmol. 1972;87(5):497-506.
20. Simmons RJ. Malignant glaucoma. $\mathrm{Br}$ J Ophthalmol. 1972;56(3):263-72.

21. Gonçalves JO. Glaucoma maligno e manitol. Rev Bras Oftalmol.1966;25(2):139-42.

22. Shaffer RN. The role of vitreous detachment in aphakic and malignant glaucoma. Trans Am Acad Ophthalmol Otolaryngol. 1954;58(2):217-31.

23. Epstein DL, Hashimoto JM, Anderson PJ, Grant WM. Experimental perfusions through the anterior and vitreous chambers with possible relationships to malignant glaucoma. Am J Ophthalmol. 1979;88(6):1078-86.

24. Quigley HA, Friedman DS, Congdon NG. Possible mechanisms of primary angle-closure and malignant glaucoma. J Glaucoma. 2003;12(2):167-80. Review.

25. Trope GE, Pavlin CJ, Bau A, Baumal CR, Foster FS. Malignant glaucoma. Clinical and ultrasound biomicroscopic features. Ophthalmology. 1994;101(6):1030-5.

26. Liu L, Wang T, Li Z. [Studies of mechanism of malignant glaucoma using ultrasound biomicroscope]. Zhonghua Yan Ke Za Zhi. 1998;34(3):178-82, 10. Chinese.

27. Liebmann JM, Weinreb RN, Ritch R. Angle-closure glaucoma associated with occult annular ciliary body detachment. Arch Ophthalmol. 1998;116(6):731-5.

28. Zhou WB. [Biometric measurements in malignant glaucoma]. Zhonghua Yan Ke Za Zhi. 1983;19(1):4-6. Chinese.

29. Lowe RF. Malignant glaucoma. Trans Ophthalmol Soc Aust. 1955;15:67-71.

30. Leroux-Lesjardins S, Massin M, Poujol J. Étude biométrique du glaucoma malin. Arch Ophtalmol (Paris). 1977;37(8-9):523-30.

31. Malta RFS, Susanna Júnior R, Ramalho MAF, Cunha SL. Biometria no glaucoma maligno. Rev Bras Oftalmol. 1990;49(1):60-2.

32. Calixto N, Cronemberger S. Glaucoma simples $\mathrm{x}$ glaucoma agudo: estudo eco-biométrico. Arq Bras Oftalmol. 1986;49(1):1-8.

33. Mérula RV, Cronemberger S, Diniz Filho A, Calixto N. New comparative clinical and biometric findings between acute primary angle-closure and glaucomatous eyes with narrow angle. Arq Bras Oftalmol. 2010;73(6):511-6.

34. Diniz Filho A, Cronemberger S, Mérula RV, Calixto N. Comparative biometric study between plateau iris configuration and primary open angle glaucoma with narrow angle. Arq Bras Oftalmol. 2009;72(3):302-7.

35. Tello C, Chi T, Shepps G, Liebmann J, Ritch R. Ultrasound biomicroscopy in pseudophakic malignant glaucoma. Ophthalmology. 1993;100(9):1330-4. Erratum in Ophthalmology 1993; 100(12): 1747.

36. Park M, Unigame K, Kiryu J, Kondo T. Management of a patient with pseudophakic malignant glaucoma; role of ultrasound biomicroscopy. Br J Ophthalmol. 1996;80(7):676-7.

37. Cavalcanti HDO, Ventura AGM, Lobato FT, Araújo Z, Tito IRP. Biomicroscopia ultra-sônica no glaucoma maligno. Rev Bras Oftalmol. 2001;60(1):14-8.

38. Epstein DL, Steinert RF, Puliafito CA. Neodymium-YAG laser therapy to the anterior hyaloid membrane in aphakic malignant (ciliary block) glaucoma. Am J Ophthalmol. 1984;98(2):137-43.

39. Brown RH, Lynch MG, Tearse JE, Nunn RD. Neodymium-YAG vitreous surgery for phakic and pseudophakic malignant glaucoma. Arch Ophthalmol. 1986;104(10):1464-6.

40. Herschler J. Laser shrinkage of the ciliary processes. A treatment for malignant ciliary block) glaucoma. Ophthalmology. 1980;87(11):1155-9.

41. Bresson Dumont H, Ballereau L, Lehoux A, Santiago PY. [Diode laser in "Malignant Glaucoma" treatment]. J Fr Ophtalmol. 2006;29 Spec 2:73-7. French.

42. Chandler PA, Simmons RJ, Grant WM. Malignant glaucoma. Medical and surgical treatment. Am J Ophthalmol. 1968;66(3):495-502. 
43. Weiss H, Shin DH, Kollarits CR. Vitrectomy for malignant (ciliary bolck) glaucomas. Int Ophthalmol Clin. 1981;21(1):113-9.

44. Byrnes GA, Leen MM, Wong TP, Benson WE. Vitrectomy for ciliary block (malignant) glaucoma. Ophthalmology. 1995;102(9):1308-11.

45. Harbour JW, Rubsamen PE, Palmberg P. Pars plana vitrectomy in the management of phakic and pseudophakic malignant glaucoma. Arch Ophthalmol. 1996;114(9):1073-8.

46. Tsai JC, Barton KA, Miller MH, Khaw PT, Hitchings RA. Surgical results in malignant glaucoma refractory to medical or laser therapy. Eye (Lond). 1997;11(Pt 5):677-81.

47. Lois N, Wong D, Groenewald C. New surgical approach in the management of pseudophakic malignant glaucoma. Ophthalmology. 2001;108(4):780-3.
48. Malta RFS. Nanoftalmia. Cirurgia de trabeculectomia e descompressäo das veias vorticosas associada ao tratamento profilático do glaucoma maligno.1993;52(4):69-72.

49. Chaudhry NA, Flynn HW Jr, Murray TG, Nicholson, Palmberg PF. Pars plana vitrectomy during cataract surgery for prevention of aqueous misdirection in high-risk fellow eyes. Am J Ophthalmol. 2000;129(3):387-8.

\section{Autor correspondente:}

Sebastião Cronemberger

Rua Martim de Carvalho, no 410 - apto. 501 - Santo Agostinho CEP 30190-090 - Belo Horizonte (MG). Brasil

E-mail: secronem@gmail.com 